cabo de 15 dias de traiamento obteve alta, continuando naturalmente as dilatações e instillações.

Hoje, isto é, anno e meio após a injecção de electrargol, ainda não se manifestou o menor symptoma para o lado do testiculo que o obrigára a guardar o leito por quatro mezes.

Esta observaçāo por si só vale para a consagração de um methodo.

São Paulo. 30 de Abril de 1921.

\title{
Sobre um cáso de distomatose produzida pelo clonorchis sinensis
}

\author{
PELO DOUTORANDO \\ CARLOS NAPOLEÃO LATERZA
}

(Communicação feita á Sociedade de Medicina e Cirurgia de S. Paulo.)

ANAMNESE - Trata-se de um japonez. K. T., com trinta annos de irlade. casado, trabalhador, residente no Brasil ha cinco annos.

Entrou para a Segunda Enfermaria de Medicina de Homens, z cargo do prof. Dr. Rubião Meira, a 14 de outubro de 1919.

Trata-se de um homem de estatura pequena, porém, de constituição robusta.

Recolheu-se ao Hospital da Santa Casa, porque estava muito edemaciado e com muita fraqueza, vendo-se assim impossibilitado de trabalhar

INTERROGATORIO - ANTECEDENTES HEREDITARIOS Pae. fallecido de dysenteria. Mãe, fallecida de senilidadle. Irmãos : quatro ao todo, sadios.

ANTECEDENTES PESSOAES - Não se lembra de ter tido molestias peculiares á infancia Nega molestias venero-syphiliticas.

HISTORIA ANTERIOR DA MOLESTIA - Em janeiro de 1918 ficou com o corpo todo edemaciado (anasarca); chamou o medico que, com tratamento adequado, conseguiu cural-o, sendo que em agosto estara completamente restabelecido. Diz o doente que o diagnostico que o medico fez foi de nephrite. Actualmente repetiu-se a mesma molestia, que se inicion com edema dos membros inferiores. generalisando-se por todo o corpo. Impossibilitado de trabalhar viu-se na contingencia de se recolher ao Hospital para o seu tratamento.

SYMPTOMATOLOGIA - Lamenta-se o doente de muita fraqueza. cephaléa e dores d ffusas pelo corpo. Apresenta-se edemaciado, com anasarca, isto é. com edema dos membros inferiores. abdomen. membros superiores. thorax. faces e palpebras. 
Tem ganglios epithrocleanos.

Retumbancia da segunda bulha no fôco aortico.

EXAME DE LABORATORIO - Reacção de Wassermann $(+++)$ Bem positiva.

EXAME DE FEZES - Caractéres urganolepticos: - Pastosas, côr de café, cheiro fecaloide.

Exame microscopico. - Revelou raros ovos de Clonorchis sinensis.

ANALYSE DE URINA - Verificou-se uma forte olyguria pela colheita de urina durante vinte e quatro horas.

Albumina - Grande quantidade (20 grs. por mil).

Assucar - Após decantação pelo liquido de Courtone reduziu fortemente o licor de Fehling e o reactivo de Nyländern, haviendo portanto, no caso, notavel quantidade de glycose, que não foi dosada.

Sedimento - Cellulas epitheliaes - algumas.

Hematias - raras.

Leucocytos - raros.

Cylindros - numerosos, granulosos

Crystaes - não ha.

N. B. A anamnese do doente foi muito difficil por elle não conhecer o nosso idioma.

\section{IMPORTANCIA DA PRESENTE COMMUNICAÇÃO}

- O ponto capital da questão é o facto de parecer que é o primeiro caso a assignalar no Brasil e não sei bem se na America do Sul.

Por uma carta que escrevi ao Sr. Dr. Adolpho Lutz, de Manguinhos, obtive uma resposta na qual o illustre parasitologista diz o seguinte: - "O Clonorchis é um parasita apparentemente commum em certas regiões, e frequente entre japonezes emigrados, como foi identificado em Cuba e na America do Norte" Parece, pois, que ainda não foi verificado na America do Sul.

$\mathrm{E}$ tambem de importancia o seu conhecimento, agora que a immigração japoneza está se intensificando para a America do Sul. E já não é n primeiro caso que os japonezes têm exportado porque o professor Dr. A. Carini teve occasião de encontrar no escarro de um japonez os ovos de Paragonimus Westermanni.

Em se tratando de um assumpto muito pouco conhecido entre nós procurei fazer um eschema do estudo completo que até hoje tem sido publicado.

HISTORICO - Origem do termo - $\beta \dot{\lambda} \omega \nu$, Kĩuvós (ramos) + òoxis (testiculos) isto é, testiculos ramificados.

Descoberto em 1874 quasi que simultaneamente por Mac Connell e Mac. Crregory, foi descripto em 1875 por Cobbold com o nome de Distomum sinensis.

Em 1883, Baelz, que ignorava os trabalhos dos medicos inglezes. fez. na mesma época descripções importantes no Japão e acreditou ter encontrado duas novas especies que denominou: Distoma hepatis endemicum, sive, perniciosum e Distoma hepatis inocuum.

W. Taylor, Isao Ijiana e R. Blanchard recunheceram a identidade do parasita descripto por Cobbold e daquelles encontrados por Paelz.

Eim 1895, R. Blanchard incluiu o Distoma chinez no genero Opis= 
torchis, que elle estabelecia para os distomas cujos testiculos se acham atraz do ovario.

Em 1907 Loos collocou-o no genero Clonorchis, creado para os trematoides cujos testiculos atraz do ovario sāo ramificados, reservando o nome de Opistorchis para aquelles cujos testiculos são lobados.

Recentemente Verdun e Bruyant distinguiram duas variedades de Clonorchis Sinensis: uma variedade Major, na qual o verme adulto tem treze a dezenove millimetros die comprimento sobre tres a quatro millimetros sobre 2 millimetros de largura, e cujos ovos teriam 26 parasita, que corresponderia ao Distomum hepatis innocuum de Baelz. frequente na China, seria raro no Japão.

A variedade Minor, em que o verme tem um comprimento de 10 a13 milimetros sobre 2 milimetros de largura, e cujos ovos teriam 26 micra por 15 micra, referir-se-ia ao Distoma hepatis endemicum, sive; perniciosum de Baelz. Esta veriedade seria muito commum no Jopão, em Tonkin e em Annam.

Mathis e Leger pelos seus estudos feitos em Tonkin em. 1911 acham que não é possivel uma distinç̧ão entre duas variedades, baseada somente sobre as dimensões. Pelas medidas feitas vierificaram, medindo um grande numero de parasitas adultos, como dimensões extremas 12.5 e $20 \mathrm{~mm}$. de comprimento e 2 a $3,2 \mathrm{~mm}$. de largura.

SYNONIMIA - Distomum sinensis, Cobbold, 1875; D. spathulatum, Leuckart, 1876; Distomum hepatis innocuum, e Distomum hepatis en= demicum, sive, perniciosum, Baelz, 1883; Opistorchis sinensis, Blanchard, 1895; Clonorchis sinensis, Loos, 1907.

HABITAT - Nos canaliculos biliares do homem; nos canaliculos biliares do cão e do gato.

DISTRIBUIÇÃO GEOGRAPHICA - China, Japão, Annam e India.

DESCRIPÇẢO DO VERME-E' um plathelmitho, trematoide, distomideo ou fasciolideo do genero Clunorchis, tendo o corpo não segmentado, foliaceo, provido de um tubo digestivo sem anus e de duas ven-
tosas.

Corpo achatado, de côr avermelhada, com a parte anterior estreitada, apresentando duas ventosas, uma oral, outra ventral, approximadas, tendo ramos intestinaes longos e simples que vão até á extremidade posterior do corpo; - póro genital logo adiante da ventosa ventral; testiculos ramificados, collocados atraz do utero; i : utero contem numerosos laços com innumeros ovos pequenos; póro excretor terminal.

VARIEDADES - Verdun e Bruyant (1908) descrevem duas variedades de Clonorchis sinensis: - o C. S. major e o C. S. minor. De seus estudos recentes, C. Math is e M. Leger (1911) concluiram que não ha razão de ser para duas variedades de Clonorchis, baseada essa distincção somenlte subre a's dimenisões, conforme Bruyant e Verdun querem; e tendo medido um certo numero de exemplares adultos, encomprimento sobre $2 \mathrm{~mm}$. a $3,2 \mathrm{~mm}$. de largura.

Verdun e Bruyant dão para a variedade major 13 a $20 \times 3$ a $4 \mathrm{~mm}$. e para a variedade minor 10 a 13 × a $3 \mathrm{~mm}$.

Os ovos são pequenos, ovoides, de côr amarellada, apresentando numa extremidade um operculo e na outra uma pequena ponta em largura.

EVOLUÇÃO - E' desconhecida. 
Pela girande analogia que apresenta com o distoma do figaldo, da Europa, a Fascicola hapatica, e com o pequeno distoma, o Dicrocoelium lanceatum, acredita-se que é no estado de cercarias que os distómas chinezes plenetram no tubo digestivo do homem.

Si as cercarias estão livres na agua, ellas são absorvidas directamente: si estão encystadas, quer sobre uma planta aquatica, quer no tecido de um mollusco ou de um peixe, a infestação deve fazer-se por intermedio desses elementos consummados crús ou cosildos insufficientemente.

INFESTACÃO E PROPHYLAXIA - Dada a incerteza que se tem sobre a infestação tambem mais incerta é a prophylaxia, visto que esta depende incontestavelmente daquella.

Billet incrimina um mollusco de genero Melania ou talvez Palu= dina Laosensis no qual encontrou esporocytos.

Segundo Kastsurada, o homem se infestaria, quer comendo certos peixes, quer directamente, sem hospede intermediario, bebendo agua polluida ou ingerindo plantas aquaticas que conteriam cercarias encystadas.

Kobayaski provou a sua hypothese, pois conseguiu infestar experimentalmente gatos, coelhos e cobayas com cystos encerrados em musculos de diversos peixes de agua doce da provincia de Okayama. principalmente Pseudorasbora e Leucogobia Güntheri.

Fraisisinet indica que segundo Lutz a Limnea Peregrata sierila o hospede de escolha. Os indigenas fariam grande consumo deste mollusco que figuraria em todos os mercados e que seria denominado "côn hop"

Mathis e Leger verificaram que nenhum tem esse nome e que a Liminea Peregrata não entra na alimentação dos anamitas. Acham que Fraissinet confundiu "côn hop" com "con ôc" que é o termo generico, com que os indigenas de Tonkin chamam todos os mariscos aquaticos.

Em resumo, o desenvolvimento genetico do Clonorchis sinensis é até agora hypothetico.

MODO DE FIXAÇÃO - A sua fixação é feita pela applicação das ventosas ás paredes dos canaes biliares. Alimentam-se de bile e de sangue.

PATHOLOGENIA - Os distomas em geral exercem sobre o organismo. - a) uma acção espoliadora: b) uma acção mechanica; c) uma acção irritativa: d) uma acção toxica ou talvez bacterifera.

A) - Acção Espoliadora - Os coecuns intestinaes de um Distoma encerram uma massa escura que sahe á pressão e que muitos auctores consideram como bile. - Raillet provou que se alimentam de sangue.

A perda de sangue é relativamente pequena, entretanto, prolongando-se, póde acarretar enfraquecimento urganico.

B) - Acção Mecanica - Quando são numerosos obstruem os canales biliares e mesmo os pancreat cos. Podem, assimi produzir uma ictericia de retenção mais o menos pronunciada. Podem comprimir certos pontos do systema venoso porta, dando origem á ascite éa hypertrophia lienal.

C) - Acção Irritativa - Vide anatomia pathologica.

D) - Acção Toxica e Bacterifera - As lesões hepaticas são muito pouco importantes, comparando-as $\mathrm{cm}$ as que produziria um cysto hydatico volumoso, frequentemente bem tolerado pelo organismo, graças á grande plasticidade do figado. 
Lim muitos casos, entretanto, a distomatose hepatica é grave, gravidade essa ligada provavelmente ás substancias toxicas lançadas pelos distomas na corrente circulatoria.

A cachexia aquosa produzida pela Fasciola hepatica e pelo Dicroelium lenceatum em certos animaes, é, comtudo, comparavel, a té certo ponto, com a anemia verminosa produzida pelo Dibotriocephalus latus on pelo Trichocephalus trichiurus.

E' admissivel que na migração dos Distomas do intestino para o figado ou para os canaes pancreaticos transportem microbios intestinaes capazes de produzir angiocholite, pancreatite, podendo mesmo inoculal-os pela picada no apparelho circulatorio.

ANATOMIA PATHOLOGICA - As lesões determinadas pelos Distomas foram descriptas por Grall, Vallot, Moty, Katsurada, Blanchard, Gaide.

Macroscopicamente se caracterizam pela congestão e hypertrophia do figado, pela dilatação dos canaes biliares obstruidos pelos Distomas.

Histologicamente se nota o espessamento das paredes dos canaes bịliares, alterações do epithelio e o apparecimento de canaliculos de neoformação. A proliferação do tecido conjunctivo_não se limita ás paredes das rias biliares; ella pode se estender a todo o parenchyma hapatico. Finalmente o processo termina em uma verdadeira cirrhose e os elementos nolires soffrem a degenerescencia graxa ou granulosa.

Anatole Leger occupou-se recentemente, re novo, do estudo anatomo-pathologico do figado parasitado pelo Clonorchis sinensis. Notou particularmente a reacção dos canaes biliares infestados, sob a forma de produç̧ão adenomatosas ou papillomatosas, ás vezes polycysticas. verdadeiras neoplasias benignas provocadas pelos parasitas. Elle approxima estes phenomenos reaccionarios daquelles provocados, p. e x.. pelos de Bilharzias no recto e na bexiga.

Sabrazés e Leger notaram uma eosinophilia local de graú elevado nos figados parasitados. Esta reacção eosinophilica, constituida pelo apparecimento de varias cellulas acidophilas, uninucleadas ou polynucleadas. é de qualquer modo a resposta dos tecidos parasitados ás acçōes toxicas produzidas pelo trematode. Ella é approximada daquella assignalada, em 1903, por Sabrazés no tecido conjunctivo que envolve os cystos hydaticos.

Estas alterações avançardas permittem comprehendt $r$ o syndromo da insufficiencia hepatica observada em certos casos: - perturbaçóes da digestão e da absorpção, em seguida á parada da bile; perturbações urinarias; ascite, por compressão no figado dos ramos de divisão da veia porta; perturbações nervosas de ordem reflexa, por irritação mecanica.

Emfim pode-se suppôr que o Distoma actua tambem por'secreçôes toxicas e talvez directamente nos capillares dos canaes, semelhantemente ao facto que mencionou Raillet para a Fasciola hepatica.

SYMPTOMATOLOGIA - Quaes os symptomas determinados pelos parasitas alojados nos canaes biliares?

E' impossivel affirmar com precisão. Com effeito, não se cunhece syndrome proprio da distomatose hepatica.

Gaide resume assim o quadro clinico observado em certos casos de infestação: - "congestão do figado com hypertrophia notavel, ictericia mais ou menos accentuada sem descoramento das fezes, perturbaçõos digestivas e perturbações urinarias consecutivas, febre de typo 
irregular, bradycardia e perturbações nervosas de ordem reflexa com alguma tendencia ao coma e á hypothermia".

Sambúc relata um caso, longamente estudado, de distomatose em que foi necessario a cholecystectomia. Os symptomas apresentados lembravam os da hepatite suppurada e da lithiase biliar: dôres hepaticas lancinantes fazendo pensar nas dôres de calculose, escapulalgia, hypertrophia consideravel do orgão, febre intensa, vomitos biliosos abundantes. As puncções do figado só tendo dado bile, foi estabelecido o diagnostico de angiocholite com cholecystite. No decorrer da operação verificou-se a sahida de numerosos distomas.

Notamos na observação de Sambúc a erupção de urticaria muito forte e tenaz, sob́revinda após as puncções, e que era, em todos os pontos, identica ás erupções que succedem ás puncções do cysto hydatico do figado.

Quando o figado é parasitado por numerosos Distomas (avaliou Blanchard em mais de dez mil o numero de parasitas que encerrariam os canaliculos biliares do figo de um anaumita vindo dos hospitaes de Hanoi), pode dahi resultar uma insufficiencia hepatica.

Nos casos extremos. Taylor assignalou, no periodo terminal da anasarca. uma diarrhéa difficil de dominar. finalmente cachexia, um enfraquecimento progressivo e a morte.

Billet, em Caobang, em 1893, attribuiu á distomatose a morte subita de um anamita que se pensava ter sido assasinado. Os canaliculos de vesicula biliar estavam distendidos e continham numerosos Clo= norchis sinensis. O tecido hepatico apresentava-se fortemente esclerosado, havendo, além disso, pleur.sia e pericardie purulentrals.

Mas, nos casos em que a infestação é ligeira, ella passa absolutamente despercebida, e só o exame repetido das fezes permitte saber que o figado está parasitado.

Grall crê que os medicos do Japão têm sobrecarregado o quadro clinico da molestia. Para elle o Distoma chinez apenas determina um estado doentio, e a morte, quando sobrevem deve ser attribuida a uma infestação intercurrente.

Mathis e Leger, em 1906, tiveram a idéa de pesquisar a insufficiencia hepatica pela prova do azul de methyleno. Foi verificada, nos portadores de Distoma, uma diminuição da duração total da eliminação, um retardamento no apparecimento do maximo da intensidade de eliminação, e intermittencias precoce no curso de eliminação. Este rythmo polycylico em particular é o que se observa nos ictericos chronicos e no figado cardiaco em gratu adiantado.

A formula leucocytaria. estabelecida em trinta e quatro indigenas portadores de Distomas. só ou com associação de outros helminthos. nada têm de caracteristica. O augmento da taxa de acidophilos, nos casos difficeis, serve de elemento de diagnostico differencial cóm a hepatite suppurada. sendo que nesta se encontra hypo-eosinophilia.

DIAGNOSTICO -.. O diagnostico é quasi impossivel de se fazer. sobretudo nos paizes em que grassa o impaludismo. O exame de fezes: é o unico meio que pode descobrir a origem das pertubaçōes hepat:cas nesses casos, como no caso presente em que, favorecido pelo acaso encontrei o Distoma, porque geralmente a presença de um pequeno numero desse parasita no figado, passa despercebida e a sua presenca só é revelada pelo exame das fezes ou pela necroscopia.

N. B. - Este diagnostico foi confirmado pelo Professor Dr. Celestino Bourroul, lente de Parasitologia da Faculdade de Medicina e Cirurgia de S. Paulo. 
PROGNOSTICO - A infestação intensa pelo Clonorchis sinensis é uma das mais graves molestias parasitarias - nos paizes em que se encontra - visto a impossibilidade de agir sobre os trematodes.

Quando os parasitas são em pequeno numero, o portador pode viver por longo tempo.

E' de notar a longevidade do Clonorchis, o que explica a facilidade e a possibilidade de accumulo desse parasita alojados nas vias biliares. TRATAMENTO - Foi empregado o benzoato e o salicylato de sodio, sem resultado.

Por emquanto tem sido o tratamento puramente symptomatico.

\section{Problema Vital}

Não existe talvez, no seio do corpo discente da nossa Faculdade, problema tão discutido e realização tão desejada como a do reconhecimento da Escola, que frequentamos. Não existe tamibem para Iús causa mais bem amparada pela Justiça. E' que tal aspiração se nos depara como uma necessidade e consegui-la é problema vital.

Effectivamente, as condições de meio encontradas pelos medicos å Faculdade de S. Paulo, não são das mais propicias para o exercicio de sua profissão. Vencidos os seis longos e trabalhosos annos do curso, o novo graduado tem de lutar dentro dos limites do Estado, hoje bastante pequeno para campo onde se desenvolva a actividade de tantos companheiros de officio, que o procuram para o exercicio da carreira. D'ahi a competição.

E se esta é legitima, nada tem de iniquo para os que a intentam, claro é que as desvantagens sempre existem para os que são obrigados neste terreno a enfrenta-la, sem faculdade de procurar outro ambiente, que não o marcado pelas relativamente estreitas balisas estudoaes. Fica, pois, o recem-formado cingido dentro de tal limite; e, consideralo o numero sempre crescente dos medicos graduados por outras Escolas que acorrem ao nosso Estado, principalmente extrangeiros, ver-se-á claramente que aquellas desvantagens augmentam tambem gradativamente para os novos medicos que aos pcucos vão sendo formados pela nossa Faculdade.

Poder-se-á objectar que o territorio assim marcado é vasto e sufficiente, não só agora mas no futuro, quando crescer o numero de medicos e com elle, parallelamente, o da população. Argumentos, com leve tinta de jacobinismo, procurarão demonstrar que até ha vantagem no facto dos medicos paulistas serem obrigaldos a enfrentar o elemento forasteiro nos nucleos mais habitados do Paiz, ccmo o nosso Estado. 